\title{
Comparison of Basal Reinforced and Unreinforced Embankments on Soft Ground by Centrifuge Model Tests
}

\author{
Di WU \\ College of Architecture and Transportation Engineering \\ Guilin University of Electronic Technology \\ Guilin, China \\ E-mail: adi823@163.com
}

\author{
Qian LI \\ College of Architecture and Transportation Engineering \\ Guilin University of Electronic Technology \\ Guilin, China \\ E-mail: m13998438015_1@163.com
}

\author{
Dan LI \\ College of Architecture and Transportation Engineering \\ Guilin University of Electronic Technology \\ Guilin, China \\ E-mail: 764937566@qq.com
}

\begin{abstract}
In recent years, the basal reinforcement technology, particularly with geogrid, had been widely used in soft soil treatment to stabilize embankment slopes in China. In this paper, two centrifugal model tests were performed to compare the reinforced and unreinforced embankments as well to investigate the influence of geogrid reinforcement on the settlements of embankment and ground. The following conclusions were obtained: (1) The total settlement of the embankments as well as the differential settlement of the embankment surface were reduced by adopting the geogrid reinforcement in the cushion. (2) The interaction between geogrid and soil made the reinforced cushion to play a more important role compared with the unreinforced cushion. (3) Basal geogrid reinforcement can increase the integrity of the embankments.
\end{abstract}

Keywords-Basal reinforced embankment; Centrifuge model tests; soft ground; geogrid reinforcement

\section{INTRODUCTION}

China is committed to developing the infrastructures in the western area of the land to make the remote area more prosperous. With this strategic development, more and more transportation lines have to be built on soft soil ground or other special ground. Improving the soft soils and making the embankments stable is one of the challenges existing in these developments.

It is well known that the soft soil will be compressed and deformed when the embankment subjects to loads or self-weights[1-3]. Reinforcement technology has been widely used, as it can reduce the vertical settlement significantly. It is also observed that horizontal displacement of the slope is also reduced when adding reinforcing material into the soils in expressway embankment slope. Moreover, the stability of the embankment is enhanced.

For more than 20 years, various approaches, including scale model tests, centrifugal model tests and practical prototype observations, have been taken to obtain a deeper understanding of the working principles and deformation characteristics of reinforced embankments[4-6].

Centrifugal model tests were adopted to study the mechanism and the effects of reinforcement for embankment in soft soils. This paper introduces the tests in details, which would deeply and systematically study the load transmission mechanism of reinforced embankment. In addition, the paper would also study the design method of the reinforced embankments. Two sets of centrifugal model tests were carried out to study the effect of embankment reinforcement. The blue model G1 was used to replace the original model. Based on the experimental analysis data of the ground deformations and road settlement, experiments were conducted to analyze the effect of the reinforcement on the load transmission and the deformation characteristics of the embankments.

\section{Centrifuge Model Tests}

\section{A. Experimental Facility}

As shown in Fig. 1, the experiment was carried out with the TLJ-150 compound geotechnical centrifuge testing facility. The test equipment had a maximum centrifugal acceleration of $200 \mathrm{~g}$, an effective rotation radius of $3.0 \mathrm{~m}$, and the centrifuge capacity of $150 \mathrm{~g} \bullet$. And the effective volume of the experimental model box was $0.80 \mathrm{~m} \times 0.50$ $\mathrm{m} \times 0.50 \mathrm{~m}$ (length $\times$ width $\times$ height .

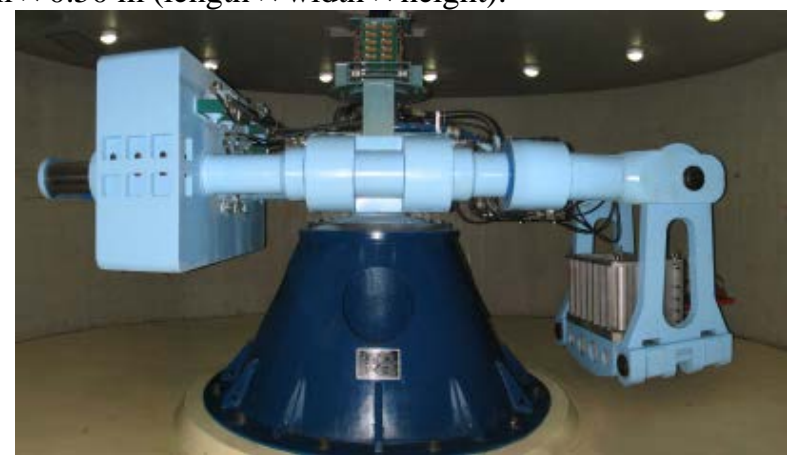

Figure 1. Geotechnical centrifuge facility 


\section{B. Test Arrangement}

The experiment simulates a real embankment in engineering practice as a model. The height of the simulation object (prototype) was $6 \mathrm{~m}$, the width is $16 \mathrm{~m}$, and the slope is set as 1: 1.5 (vertical: horizontal). No rigid piles are set in the test model. The thickness of the stiffened cushion (G1) was $0.6 \mathrm{~m}$. Under the embankments, the soft soil layer was $16 \mathrm{~m}$ thick laying on a sandy soil stratum. he experiment model selection rate is set to $\mathrm{N}=80$, which means the real dimensions of the embankment and laying soils will be reduced 80 times. The dimension of the model is shown in Fig. 2.
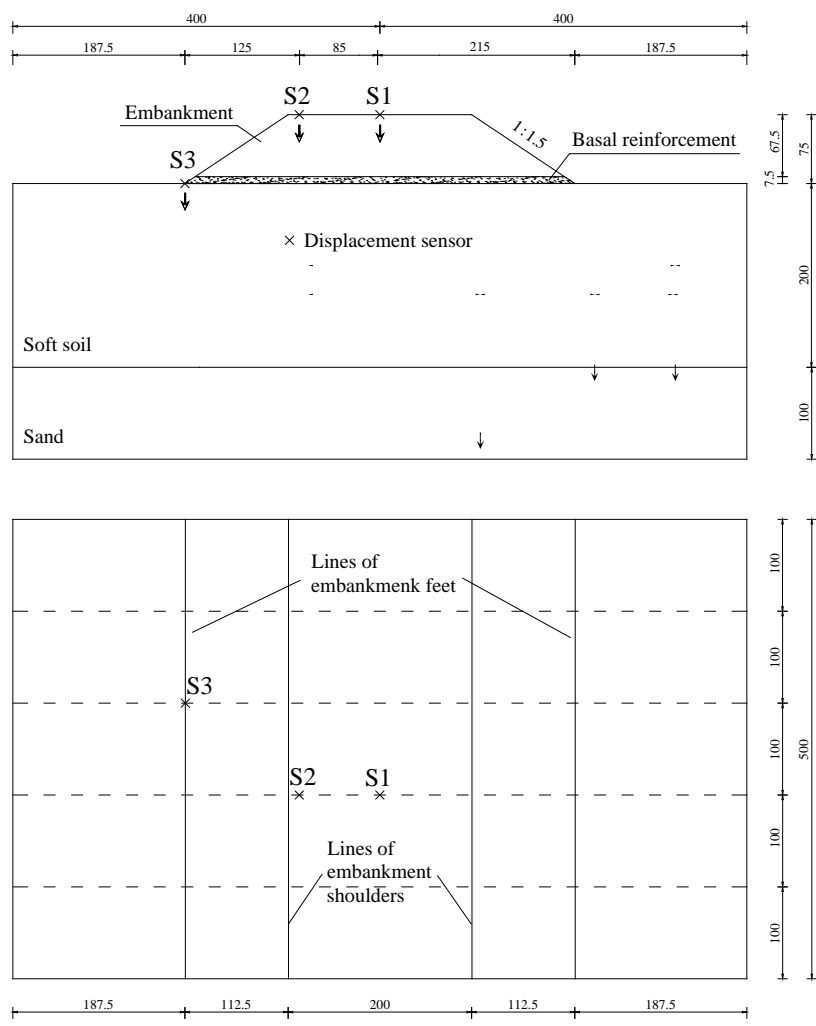

Figure 2. Dimensions of models and arrangement of instruments (unit: $\mathrm{mm})$

As shown in Tab. 1, two sets of reinforced embankment centrifugal model tests were carried out. An alternative of geogrid, G1, was also provided. Tab. 2 shows the ultimate tensile strength, the elongation and the aperture of the alternative material and prototype geogrid. The additional G1 layer of reinforcement was compared with the nonreinforced material.

\section{Test Materials and Preparation}

The tensile test was carried out to obtain the material property of G1 material, the model and prototype grid. Test results were summarized in Tab. 3 . It is found the tensile strength of G1 was similar to the prototype grid, which has was smaller mesh and dense grid.

The centrifugal model test for the foundation layer was carried out for the upper soft soil and the lower sand layer, respectively. Silt clay mixed with the silt clays and the fourth layer of silt clay in Shanghai area. As shown in Tab. 3 , in routine laboratory tests, the main physical and mechanical indexes of the soft soil layer were obtained in two experimental models after the completion of the consolidation of the soil samples. The soil plasticity index was $15, \mathrm{E}_{\mathrm{s} 0.1-0.2}$ compression modulus of $2.71 \mathrm{MPa}$, and the permeability coefficient was $7.56 \times 10^{-9} \mathrm{~m} / \mathrm{s}$.

TABLE I. TEST ARRANGEMENT

\begin{tabular}{|c|c|c|}
\hline Test & $\begin{array}{c}\text { Number of geogrid layers in } \\
\text { the cushion }\end{array}$ & $\begin{array}{c}\text { Arrangement of geogrid in } \\
\text { the cushion }\end{array}$ \\
\hline M1 & 1 (Basal reinforced) & Bottom of the cushion \\
\hline M2 & 0 (Unreinforced) & none \\
\hline
\end{tabular}

TABLE II. EXPERIMENTAL PARAMETERS AND APERTURES OF GEOGRIDS

\begin{tabular}{|c|c|c|c|}
\hline Geogrids & $\begin{array}{c}\text { Prototype } \\
\text { geogrid }\end{array}$ & $\begin{array}{c}\text { Switched } \\
\text { prototype geogrid }\end{array}$ & $\begin{array}{c}\text { G1 } \\
\text { (geonet) }\end{array}$ \\
\hline $\begin{array}{c}\text { Tensile force at 2\% } \\
\left.\text { elongation/(kN•m }{ }^{-1}\right)\end{array}$ & 30.4 & 0.38 & 0.30 \\
\hline $\begin{array}{c}\text { Ultimate tensile } \\
\left.\text { strength/(kN•m }{ }^{-1}\right)\end{array}$ & 87.2 & 1.09 & 1.28 \\
\hline Ultimate elongation/\% & 9.1 & 9.1 & 15.9 \\
\hline $\begin{array}{c}\text { Geogrid } \\
\text { aperture } / \mathrm{mm}^{\mathrm{m}} \mathrm{mm}\end{array}$ & $38 \times 38$ & $0.475 \times 0.475$ & $8.0 \times 8.0$ \\
\hline
\end{tabular}

TABLE III. MAIN PHYSICAL AND MECHANICAL PARAMETERS OF SOFT SOIL LAYER IN THE MODEL FOUNDATION AFTER CONSOLIDATION

\begin{tabular}{|c|c|c|}
\hline Tests & M1 & M2 \\
\hline Water content & $35.1 \%$ & $37.2 \%$ \\
\hline Gravity & $18.59 \mathrm{kN} \cdot \mathrm{m}^{-3}$ & $18.56 \mathrm{kN} \cdot \mathrm{m}^{-3}$ \\
\hline c & $11.33 \mathrm{kPa}$ & $9.21 \mathrm{kPa}$ \\
\hline$\varphi$ & $6.23^{\circ}$ & $2.13^{\circ}$ \\
\hline
\end{tabular}

Embankments and reinforced cushions were filled with the same sand, as shown in Tab. 4. Embankment forming need to use layered manufacturing methods: The volume of each layer of sand was calculated by the dimension of embankment section with each layer $1 \mathrm{~cm}$. As the control index, the dry density was $1.620 \mathrm{~g} / \mathrm{cm}^{3}$ for compaction, so as to ensure the uniformity and the same density of the embankments.

\section{Model Dimensions and Measurements}

The size of the model was derived from the simulation object through the model rate conversion. Specific size and sensor layout are shown in Fig. 2.

\section{E. Test Procedure}

(1) According to the design of paved reinforced cushion and buried soil pressure gauge, the layered model was grounded in $80 \mathrm{~g}$ centrifugal field for $5 \mathrm{~h}$.

(2) The embankment was divided into layers with the degree of compaction as the control index, and fixed displacement sensor. 
(3) This experiment simulated the process of graded embankment loading by changing the method of acceleration. The embankment was divided into 3 levels to be filled and filled. It stopped after the completion of each level of heap $60 \mathrm{~d}$.

(4) Centrifugal model of the experiment with the specific acceleration of the course of time was shown in Fig. 3.

TABLE IV. CONTROL INDEX AND PARAMETERS OF EMBANKMENT AND CUSHION SANDS

\begin{tabular}{|c|c|c|}
\hline Sand & Embankment & Cushion \\
\hline Controlled dry density & $1.620 \mathrm{~g} \cdot \mathrm{cm}^{-3}$ & $1.620 \mathrm{~g} \cdot \mathrm{cm}^{-3}$ \\
\hline Maximal dry density & $1.742 \mathrm{~g} \bullet \mathrm{cm}^{-3}$ & $1.742 \mathrm{~g} \cdot \mathrm{cm}^{-3}$ \\
\hline Minimum dry density & $1.265 \mathrm{~g} \cdot \mathrm{cm}^{-3}$ & $1.265 \mathrm{~g} \cdot \mathrm{cm}^{-3}$ \\
\hline Compactness & $93 \%$ & $93 \%$ \\
\hline Relative compaction & 0.80 & 0.80 \\
\hline Controlled water content & $5 \%$ & $5 \%$ \\
\hline Nonuniformity coefficient & 6.0 & 6.0 \\
\hline Curvature coefficient & 1.185 & 1.185 \\
\hline Cohesive strength & $4.6 \mathrm{kPa}$ & $4.6 \mathrm{kPa}$ \\
\hline Internal friction angle & $38.2^{\circ}$ & $38.2^{\circ}$ \\
\hline
\end{tabular}

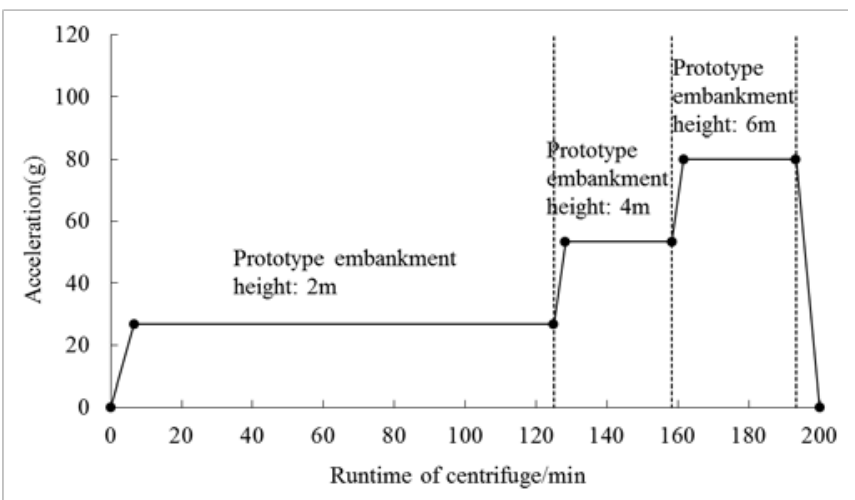

Figure 3. Loading curves of models

\section{Test Results AND Discussion}

\section{A. Deformation of Embankments and Foundation}

It can be seen from Fig. 4, Fig. 5 and Fig. 6 that the existence of the reinforcement had a certain influence on the settlement of embankments.

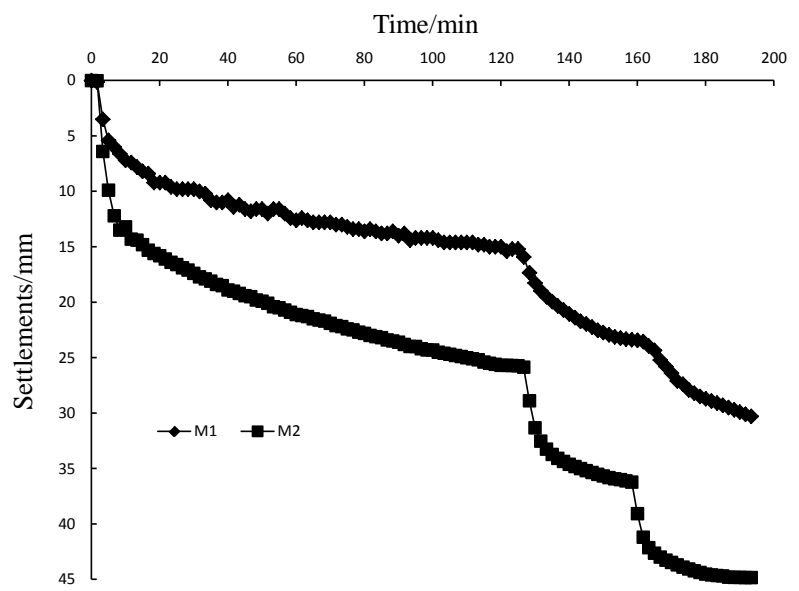

Figure 4. Settlement of the road surface in the center of embankment vs. time curves

Fig. 4 shows that the settlement curves of the road surface in the center of embankments with and without geogrid reinforcement in the cushion (M1 and M2). It shows that the settlement of M2 was larger than that of M1 by adding G1 to the cushion. When fully loaded, the settlements of M1 and M2 were $27.10 \mathrm{~mm}$ and $43.68 \mathrm{~mm}$, respectively, which showed that the reinforced cushion played an important role in reducing the surface settlement of the embankments under normal circumstances.

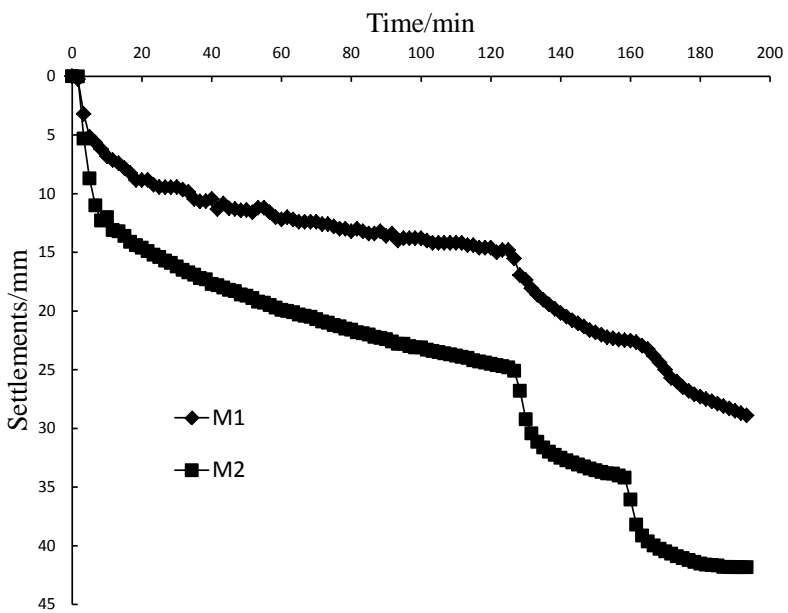

Figure 5. Settlement of the road surface at the shoulder of embankment vs. time curves 


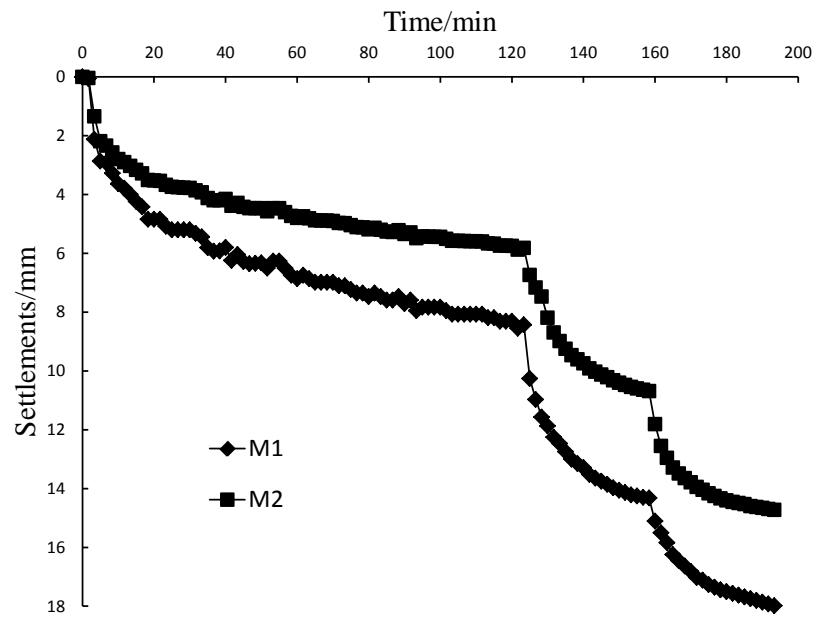

Figure 6. Settlement of the ground at the foot of embankment vs. time curves

Fig. 5 shows the settlement curves of the road surface at the shoulder of embankments with and without geogrid reinforcement in the cushion (M1 and M2). It can be seen that the trend of the settlement curves were similar with the fig. 4. When fully loaded, the settlements of M1 and M2 were $25.70 \mathrm{~mm}$ and $40.68 \mathrm{~mm}$, respectively, which were smaller than these of the embankment road surface center.

In summary, the settlement of embankment surface decreases with the reinforcement from the perspective of whether or not reinforced. This indicates that the horizontal geogrid reinforcement in the embankment cushion plays an important role in reducing the vertical settlement of the embankment surface.

Fig. 6 shows the settlement curves of the ground surface at the foot of the embankments (S3), as shown in fig. 2. It can be seen that the settlements of the reinforced (M1) and unreinforced (M2) were $17.03 \mathrm{~mm}$ and $13.95 \mathrm{~mm}$, respectively. More concentrated load on the ground surface results in a greater settlement, because the integrity ofe reinforced embankments was much better than that of the unreinforced embankments. It was further explained that the interaction between geogrid and soil could be enhanced by adding the geogrid in the cushion, and geogrid reinforced cushion play a more important role in the embankments contributed in soft ground.

\section{B. Differential Settlement of Embankments}

Fig. 7 clearly shows the differential settlements of embankment surface between center and shoulder of the road when runtime of centrifuge was $180 \mathrm{~min}$, which means full of embankment load. Differential settlements between the two points were defined as follows:

$$
\Delta S=S 2-S 1
$$

The former data in equation above were the settlement values measured by the displacement meter S2, and the latter data were the settlement values measured by the displacement meter S1. Both S1 and S2 were shown in fig. 2.

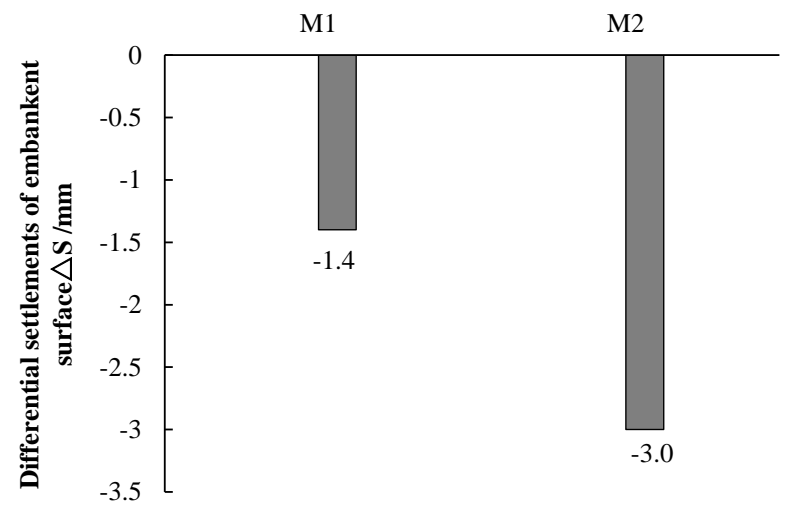

Figure 7. Differential settlements of embankment surface between center and shoulder of the road (runtime of centrifuge: 180min)

It can be seen from Fig. 7 that the differential settlements with and without reinforcement (M1 and M2) were negative. It indicates that the settlement of the shoulder of the embankment surface in this study were smaller than the center of the embankment surface whether the embankments were reinforced or not. This was because the embankment load was large for soft ground, and a sliding surface would be formed, which meant a poor stability of the embankment. So a larger settlement would be found in the center of embankment surface. Compared with M1 and M2, It can be clearly seen that the geogrid reinforcement can be more effective to reduce the differential settlement between the embankment center and the shoulder. Moreover, the reinforcement will further improve the integrity of the embankments.

\section{CONCLUSIONS}

Through two groups' embankment centrifuge model tests, the surface settlements of the embankments and the foundation were obtained. The differential settlements of embankment surface were analyzed to evaluate the overall stability and integrity of embankments enhanced by geogrid reinforcement. The following conclusions were obtained:

(1) The total settlements of the embankments could be reduced by adopting the geogrid reinforcement in the cushion, as well as the differential settlements of the surface of the embankments could be adjusted smaller.

(2) Basal geogrid reinforcement can increase the integrity of the embankments. The overall stability of embankment slope increased with a reinforced cushion, compared with the unreinforced embankments.

(3) The interaction between geogrid and soil made the reinforced cushion to play a more important role compared with the unreinforced cushion.

\section{ACKNOWLEDGMENT}

Financial support for this work is gratefully acknowledged from the Natural Science Foundation of 
Guangxi Grant 2015GXNSFBA139236 and Guangxi University Scientific Research Project Grant KY2015ZD044. All the support is greatly appreciated.

\section{REFERENCES}

[1] Bolton, M. D., Sharma, J. , "Embankments with base reinforcement on soft clay," Proceedings of International Conference on Centrifugal 94”, A. A. Balkema, Rotterdam, pp. 587-592.

[2] Cao Y. H., and Chen H. 2006. "Application of ameliorated high liquid clay to construction of expressway", Journal of Railway Engineering Society, (8), 34-37. (in Chinese)

[3] Ding, J. H., Bao, C. G. 1999. "Centrifugal model test and finite element analysis of geosynthetic-reinforced embankments on soft ground and dredger fill”, China Civil Engineering Journal, 32(1), 21-25 (in Chinese).
[4] Mandal, J. N., Joshi, A. A. 1996. "Centrifuge modelling of geosynthetic reinforced embankments on soft ground”, Geotextiles and Geomembranes, 14(2), 147-155.

[5] Xue Z. Q., Chen Y. P. 2004. "Introduction to the lime-soil treated expressway embankments along Yangzi River in Jiangsu Province”,Journal of China and Foreign Highway, 24(3), 15-17. (in Chinese)

[6] Yu, Y. Z., Zhang, B. Y., Zhang, J. M. 2005. "Action mechanism of geotextile-reinforced cushion under breakwater on soft ground", Ocean Engineering, 32(14/15), 1679-1708.

[7] Han J, Gabr M A. "Numerical analysis of geosynthetic-reinforced and pile-supported earth platforms over soft soil". Journal of Geotechnical and Geoenvironmental Engineering, 2002, 128(1): 4453.

[8] Railway Technology Research Institute. 2001. "The Design and Construction Handbook of Mixing Piled Foundation"(Machine Mixing) [M]. Tokyo: Railway Technology Research Institute. 